\title{
“THE DEVELOPMENT OF SEISMIC ZONES AND THE EVALUATION OF LATERAL LOADINGS FOR EARTHQUAKE RESISTANT DESIGN OF BUILDINGS IN PAPUA NEW GUINEA"
}

\author{
R. D. Jury, J. P. Hollings and I. A. N. Fraser \\ (Vol 15, No 3, September 1982, pp 123-140) \\ Discussion by Kevin McCue
}

\begin{abstract}
$\underline{\text { ABSTRACT }}$
A recently published seismic zoning map of Papua New Guinea does not correlate particularly well with either presentday seismicity or tectonic models of the region. Several reasons are given and a modified version of the map is presented for discussion and as a replacement in the Building Code.
\end{abstract}

\section{INTRODUCTION}

The seismicity of the Papua New
Guinea region has long been studied,
notably by Sieberg (1910), Gutenberg and
Richter (1954), Denham (1971), Everingham
(1974), and many others and is widely
understood; or is it? Recently there
appeared in this journal a seismic zoning
map for building construction in Papua
New Guinea (Jury et al, 1982$)$, herein
called the JHF map, which is at odds with
conventional theories on the seismicity
and tectonics.

\section{ADEQUACY OF MODEL}

Such maps are normally produced from a listing of recent earthquakes and a locally relevant attenuation relationship convoluted with a recurrence relation, or preferably extreme value distribution, to give the estimated probabilities or return periods of specified ground motions. This appears to have been the JHF methodology but there are problems of detail. For example, the Bureau of Mineral Resources (BMR) earthquake datafile lists whichever of $\mathrm{Mb}$, ML and MS are available but rarely all three and for a period of five years only $\mathrm{Mb}$ (CGS). There is no discussion on how or whether scales were converted from one to another or which was ultimately used.

$\begin{aligned} & \text { Secondly, why did JHF use a recur- } \\ & \text { rence } \\ & \text { rather thation derived from Indonesia } \\ & \text { than for Papua New Guinea }\end{aligned}$
* $\begin{aligned} & \text { Consulting Engineering Seismolo- } \\ & \text { gist, Arawa, Papua New Guinea. }\end{aligned}$
reproduction of a computer generated plot
BULLETIN OF THE NEW ZEALAND NATIONAL SOCIETY FOR EARTHQUAKE ENGINEERING, VOL.17, NO.4, DECEMBER 1984
(Everingham, 1974) or better still, why not derive the extreme value distribution which is so much easier and a better estimate of the true return periods?

Lastly, was the attenuation relation calibrated against Papua New Guinea data? The Port Moresby Geophysical Observatory has a large collection of accelerograms, most of which were recorded on medium or soft foundations and several of them have been analysed by the BMR and others by the observatory.

The results of the number crunching are plotted and the map contoured and then usually smoothed according to precepts of the tectonics and/or the concensus opinion of a group of engineers, geologists and seismologists which has not yet happened in this case. The resultant map should, however, reflect the input.

\section{COMPARISON OF INPUT/OUTPUT}

Specifically it might be expected that the resultant map should correlate fairly closely with a map of shallow earthquakes; zone boundaries should parallel epicentre lineaments and their levels correspond roughly to the density of epicentres. The smoothing process might continue boundaries across seismic gaps if sufficient knowledge of the plate boundary whereabouts is known. Furthermore, such maps should be continuous, or nearly so, across political boundaries; different socio-economic groups might accept different levels of risk which would lead to a widening or narrowing of zones but the trends should remain.

In Figure 1 is reproduced the JHF map (their Figure 13) and in Figure 2 the 

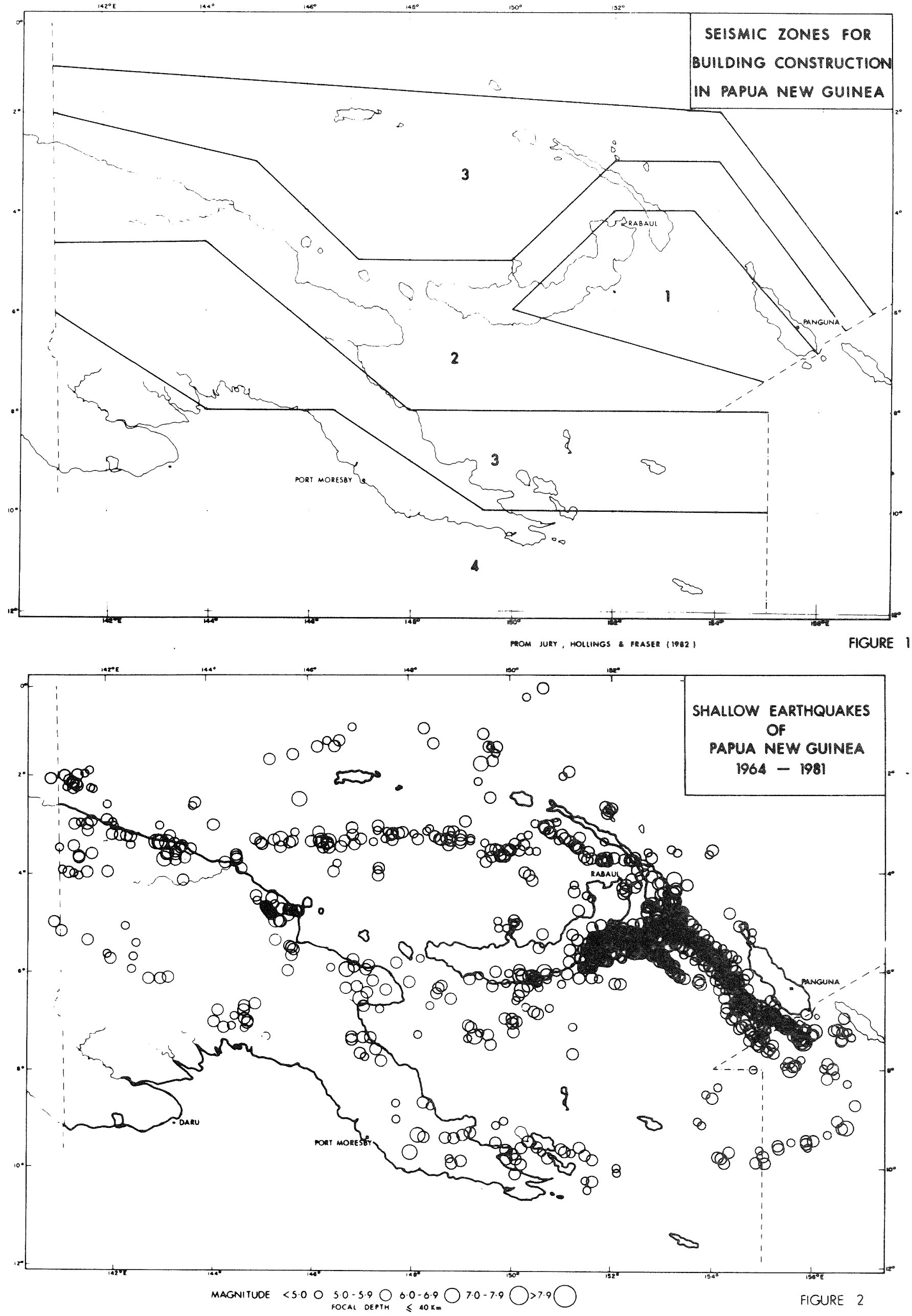
of shallow (depth 0 to 40 kilometres) epicentres from 1964 to 1981 selected from the Port Moresby Geophysical Observatory data file. Only those epicentres recorded at 10 or more stations were used.

At first glance there are some obvious similarities between the figures; the highest activity around the northeast Solomon sea does correspond with the highest risk zone (the lowest number) and the negligible activity in the southwest of the country is assigned the lowest zone (highest number). It is refreshing to see the zone boundaries continued out to sea which must be a useful guide to engineers planning submarine cable routes or offshore oil and gas platforms but this also highlights the detailed differences between the figures:

1. Neither the Bismark sea lineament (Denham, 1971), actually a set of en echelon shears, nor the less active Solomon Sea lineament are reflected in the Figure 1 zone boundaries and each is a well recognised plate boundary (Everingham, 1974).

2. Still at sea, no epicentres occur east of the west coast of Bougainville yet the east coast rates a wide zone, in level commensurate with the New Guinea north coast or central Bismark sea where frequent large shallow earthquakes occur. Attenuation of intensity is very rapid across the Bougainville arc as isoseismal maps testify (Everingham et al, 1977), and this factor will narrow the zones.

3. The onshore earthquake activity across the New Guinea island, called the southern highlands seismic zone (Ripper and McCue, 1983) which is readily seen in Figure 2, does not appear as a separate feature in Figure 1 though almost 200 aseismic kilometres separate it from the active north coast zone. According to Ripper and McCue the level of risk there is similar to that in California and two major ( $M>7.0$ ) earthquakes have occurred along the zone since 1900. The coincidence of a broad zone of Pliocene/Quaternary faulting indicates that this is the northern edge of the Australian Plate.

4. On 9 March 1979 a large (MS 6.2) earthquake occurred 70 kilometres southeast of Port Moresby causing Modified Mercalli intensities of VI to VII in the city (Ripper and McCue, 1981). Earthquakes of similar size preceded this event on 21 May 1976 and 11 April 1978 but farther to the east. The JHF zone $3 / 4$ boundary down the peninsula runs between these earthquakes rather than paralleling the edge of the activity. The geology (Davies 1971 ) and seismicity outline this eastern boundary of the Solomon sea plate and the zone boundary should also.

It would be interesting to compare the zone boundaries across the Irian Jaya/ Papua New Guinea border, especially as the same consultants produced risk maps for both areas but unfortunately the Indonesian map was not available to me.

\section{A REVISED ZONE MAP}

Part of the problem in introducing a seismic zoning map is that it is so difficult to change, especially if the possibility of retrospective legislation is raised. This has so far not been the case in Papua New Guinea and this JHF map is the third version included in a local Building code and is, I hope, not the last.

As subject for discussion I have drawn up Figure 3 which satisfies my criticisms of the JHF version. I have accepted the need for a super zone and added a zone 0 but used no computer, no recurrence relation, no attenuation relation - just common sense. This necessitated reversing the JHF zoning convention which brings it into line with zone designations in Australia, Canada and the United states, that is, increasing number for increasing risk.

Towns such as Rabaul would then be in zone 3 rather than the super zone 4 in recognition of the fact that the Solomon sea plate boundary is $100 \mathrm{kilo-}$ metres distant. And so, unlike say san Francisco, it has little likelihood of experiencing a close great earthquake though lesser shocks rock Rabaul quite frequently due to the proximity of the Bismark sea lineament and the shallow seismicity landward of the trench.

In Figure 3 high risk areas are at plate boundaries and lowest risk areas at plate centres as might be expected. Zone boundaries are close to the edge of earthquake belts. Simple geometric considerations show that the risk halves across such edges and in addition the greatest contribution to risk comes from close, moderate, frequent earthquakes rather than distant, great, infrequent ones (Cornell and Vanmarke, 1969).

\section{MAP COMPARISONS}

Why are the maps in Figures 1 and
3 so different? Basically because Jury
et al ignored the tectonics, they used
only the set of large and major earth-
quakes to define the zones and included
early (1900 to 1964 ) epicentres which were
very inaccurately located; the epicentre
of one major earthquake, on 2 November
1923 , is probably up to 400 kilometres
in error (Everingham et al, 1977 ). Lastly
a grid spacing of one degree produces
zones which are too wide where the attenu-
ation is so high and the tectonics so com-
plex.

\section{REFERENCES}

Cornell C A and Vanmarke E H, 1969. "The Major Influences on Seismic Risk". 4th World Conference on Earthquake Engineering Chile.

Davies H L, 1971. "Peridotite-Gabbro-Basalt Complex in Eastern Papua: An Overthrust Plate of Oceanic Mantle and Crust." BMR, Australian Bulletin, 128. 
Denham D, 1971. Seismicity and Tectonics of New Guinea and the Solomon Islands. Royal Society Nz Bulletin, 9: 31-38.

Everingham I B, 1974. 'Large Earthquakes in the New Guinea-Solomon Islands Area, 1873-1972: Tectonophysics, 23: 323-338.

Everingham I B, Gaull B and Dent V, 1977. Effects of a Major Earthquake Near Bougainville, 20 July 1975: BMR Journal of Australian Geology and Geophysics, 2: $305-$ 310 .

Gutenberg B and Richter C F, 1954. "Seismicity of the Earth and Associated Phenomena." Hafner.

Jury $R$ D, Hollings $J$ P and Fraser $I A N$, 1982. The Development of Seismic Zones and the Evaluation of Lateral Loadings for Earthquake Resistant Design of Buildings in Papua New Guinea." Bulletin NZ National Society for Earthquake Engineering, 15: 123-140.

Ripper I D and McCue K F, 1983. "The Seismic Zone of the Papuan Fold Belt! BMR Journal of Australian Geology and Geophysics, 8: 147-156.

Ripper I D and McCue K F, 1981. "The 9 March 1979 Port Moresby Earthquake:. Science in New Guinea, 8 (1): 38-48.

Sieberg A, 1910. "Die Erdbebentatigkeit in Deutsch-Neuguinea (Kaiser-Wilhelmsland und Bismarkarchipel)". Petermanns Geographische Mitt, II, Heft $2 / 3$.

AUTHORS' REPLY TO DISCUSSION BY KEVIN MCCUE

The authors thank Mr McCue for his interest in their paper. Many of his criticisms and comments are, however, based on a misconception of the method outlined.

The main reason for the lack of definition of some tectonic features in the final zoning map (one of Mr McCue's major criticisms) is the attenuation relationships used in this study. The attenuation of structural response as opposed to ground acceleration is the basis of the zoning scheme and this has the effect of smoothing out the effects of many localised tectonic features especially for the return period considered (that is, 20 years). For example, consider a response level of $0.4 \mathrm{~g}$. The attenuation relationships indicate that for a short period structure on soft ground a response of $0.4 \mathrm{~g}$ will be experienced within 180 kilometres of a magnitude 7.5 or greater earthquake, and within 75 kilometres of a magnitude 7.0 earthquake.

Tectonic features of the same order in size as the above distances tend therefore to lose definition during the analysis.

Mr McCue's suggested zoning scheme is as he states based primarily on an epicentral map. It is therefore an occurrence model and should be more correctly compared with Figure 6 in our paper where the similarities are apparent rather than the response plots or the codified zoning map. Figure 6 was derived after consideration of historical earthquakes of magnitude 5 and greater and then adjusted for geological evidence. The resulting zoning map is therefore not solely reliant on a set of large and major earthquakes as Mr McCue contends. The lack of precision in location of older events is common to any seismic region. The solution is not to disregard totally these events but rather to tread carefully and to avoid reliance on suspect epicentres. An inspection of Figures $3,4,5$ and 6 indicates that Figure 5, recording historical activity for magnitudes 5 and greater, has the greatest similarity to Figure 6 as might be expected.

A major advantage of the analysis presented in the paper is that the lateral loadings experienced by structures can be directly estimated. The final choice of appropriate zone boundaries therefore reflects reasonable variations in expected lateral load rather than earthquake activity.

Several further aspects were also raised in the discussion. Mr McCue correctly observed that the BMR files rarely state all three magnitude scales. The policy followed in the study was as follows: to use $M$ when available followed by $M$ and finalty $M$. Over the range of magnitudes causing the majority of risk the likely maximum error in terms of $M_{T}$ was found to be no more than half a magnitude. This is well within the accuracy implied by any risk analysis and therefore no adjustments were made to the magnitude estimates.

Mr McCue incorrectly interprets that a recurrence relation derived from Indonesian data was used for this study. During the Indonesian Earthquake Study (ref 12 original paper) two values of ' $\mathrm{b}$ ' were used, 1.0 for asymmetric systems and 0.9 for symmetric systems. This was after a careful study of historical records of some 15 isolated tectonic systems within Indonesia. A parometric study subsequently performed indicated that provided the earthquake magnitude chosen as the basis of the recurrence model $\left(M_{L}=7.0\right.$ or greater in this study) was within the range of magnitudes producing the greatest proportion of risk then the errors in the final response values associated with the choice of the 'b' value (that is, between 0.9 and 1.0 ) were within the accuracy that is implied by the risk analysis.

It is the authors' understanding after several discussions with staff of the Seismological observatory in Port Moresby that to date very few strong motion records taken in Papua New Guinea have been analysed to produce response spectra. The authors are in total agreement with Mr McCue that once records have been analysed they should be used to confirm the acceptability of the attenuation relationship used. In the meantime the relationship used must remain one of few currently available that can be considered reasonably 
applicable to the PNG situation.

Whilst Figures 3,4 and 5 were based on contours drawn for points evaluated for a square one degree grid the risk analysis was performed based on reducing Figure 6 to a square quarter degree grid.

Finally Mr McCue has requested that the zoning maps be reviewed frequent ly on a periodic basis. The authors concur. A further advantage of the method outlined is that the calculations can be readily reviewed and repeated taking into account the latest views of seismologists, geologists, engineers and also changing trends in seismic activity.

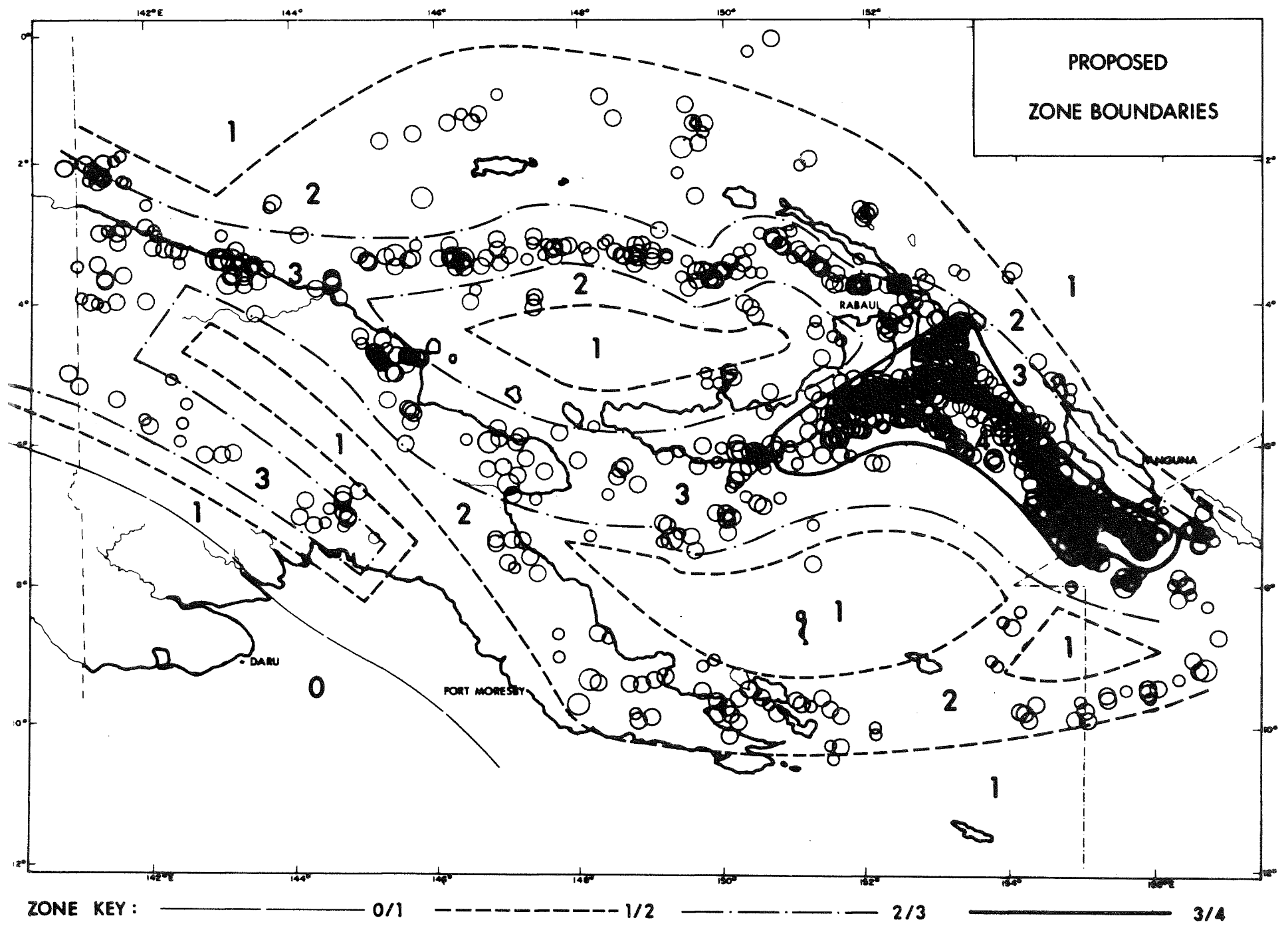

